\title{
Effectiveness of Physiotherapy in the Treatment of Hemophilic Arthropathy a Systematic Review
}

\section{Cuesta-Barriuso $\mathbf{R}^{*}$ \\ Department of Physiotherapy, European University of Madrid, Royal Victoria Eugenia Foundation, Spain \\ *Corresponding author: Cuesta-Barriuso R, Department of Physiotherapy, European University of Madrid, Royal Victoria Eugenia Foundation, Spain}

Received: July 10, 2017; Accepted: August 21, 2017; Published: October 12, 2017

\begin{abstract}
Hemophilia is a congenital coagulopathy characterized by musculoskeletal bleeding. The recurrence of bleeding in one joint causes joint deterioration known as hemophilic arthropathy. This arthropathy is characterized by chronic pain, and loss of joint mobility, muscle strength and proprioception. Prophylactic medical treatment with physiotherapy may improve the physical conditions of patients with hemophilia.
\end{abstract}

Method: A systematic search was conducted in PubMed, Science Direct, Isi Web and the specialized journal Haemophilia. The information on the intervention, control condition, study methodology and the main findings of each study were extracted and summarized critically. The methodological quality of the selected studies was evaluated using the Van Tulder and PEDro scales.

Results: Data from 10 studies fulfilled the selection criteria. Physiotherapy programs through home exercise programs and ergonomic bicycle and treadmill exercises to develop muscle strength, gait and proprioception produced significant improvements in pain perception, joint range of motion and muscle strength. Similarly, manual therapy is safe and effective in improving chronic pain and joint mobility. Finally, educational physiotherapy improves the perception of pain and the quality of patients with hemophilia. The results were less clear for social perception and attributional bias. The overall methodological quality of the study was medium-high. The power of the results, through the size of the effect was medium-high.

Conclusion: Physiotherapy interventions through educational physiotherapy, manual therapy, stretching, muscle strength protocols and cycling exercises improve pain perception, functionality, proprioception and muscle strength, and quality of life and perception of disease in patients with hemophilic arthropathy.

Keywords: Hemophilia; Joint damage; Hemophilic arthropathy; Physiotherapy; Randomized clinical trial

\section{Introduction}

Hemophilia is a hereditary and recessive disease, linked to the $\mathrm{X}$ chromosome, characterized by the deficiency of one of the clotting factors. Based on the deficit factor, there two types of hemophilia: A (FVIII deficit factor) and B (IX deficit factor), and depending on the percentage in blood of FVIII/FIX, hemophilia severity varies (severe: $<1 \%$, moderate: $1-5 \%$, and mild: $>5 \%$ ) [1]. The prevalence of the disease is 1: 5000 live births in hemophilia A and 1: 30000 live births in hemophilia B [2].

This hematological disease is characterized by hemorrhages in the locomotor system, mainly located in muscles and joints (haemarthrosis) [3]. Joint bleeding mainly occurs in knees, ankles and elbows [4]. Repeated haemarthrosis in the same joint leads to the development of synovial membrane hypertrophy, chemical and enzymatic intra articular alterations, and finally joint degeneration (hemophilic arthropathy) [5].

The onset of arthropathy presents with radiological alterations (decreased joint interline, bone deformity, and the development of osteophytes, among others), physical alterations (chronic pain, loss of range of motion and periarticular muscle strength, and altered proprioception) [6], as well as psychological alterations (decreased perception of quality of life) [7].

The Gold standard in the treatment of hemophilia is the periodic intravenous administration of the lacking clotting factor (prophylactic treatment) [8]. This therapeutic model has been shown to be the most effective in the prevention of hemorrhages and the development of hemophilic arthropathy. However, despite advances in medical treatments, adult patients and those living in developing countries have not had access to prophylaxis, thus exhibiting significant joint alterations [9].

When the joint has developed a degenerative arthropathy the therapeutic options include physiotherapeutic and orthopedic treatment with the aim of improving functionality [10]. An appropriate management of the hemophilia patient's chronic pain is essential, requiring the participation of physiotherapists in the multidisciplinary team treating patients with hemophilia [11]. Although a number of studies have been designed to assess the safety and efficacy of 


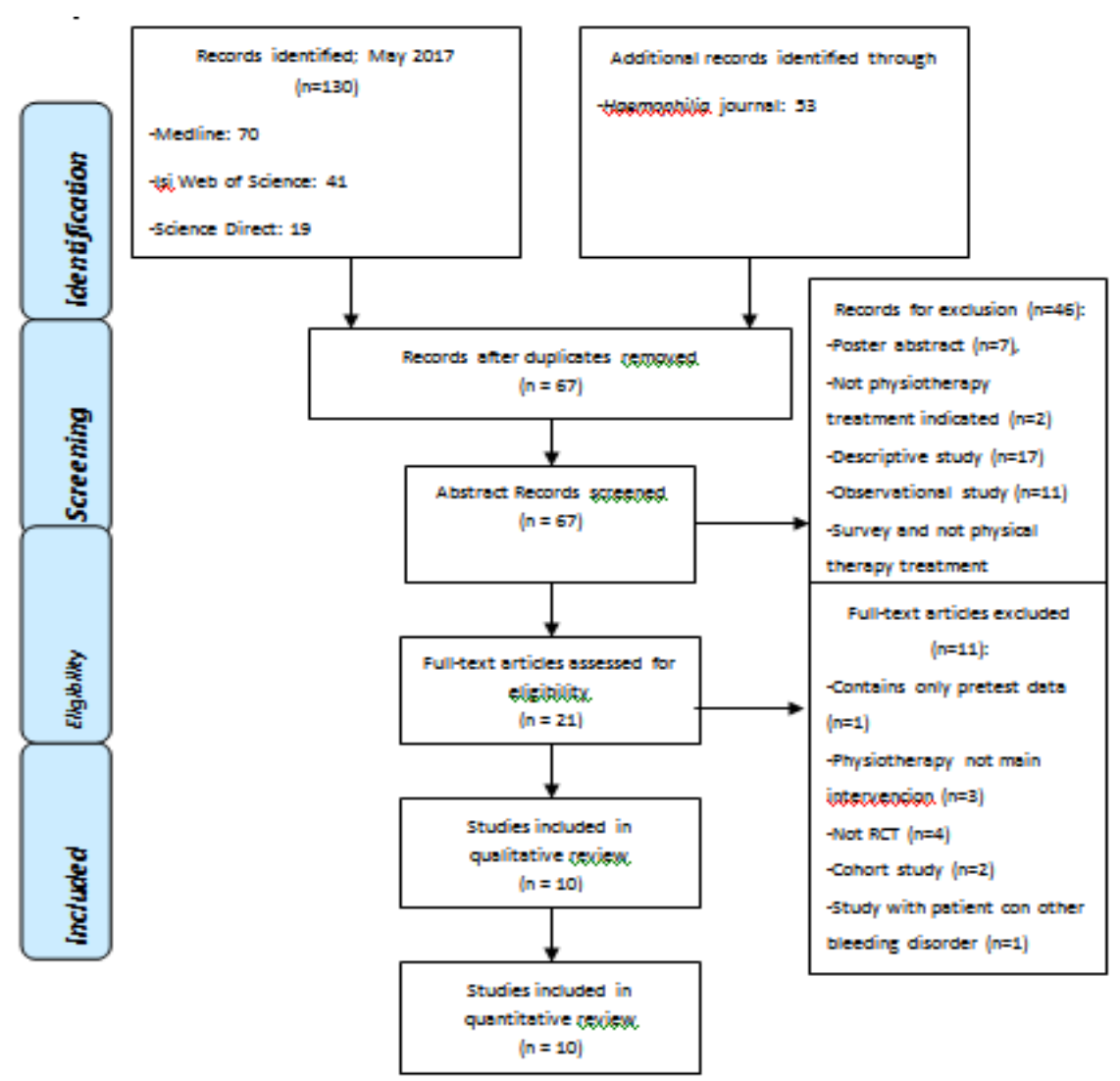

Figure 1: Flow Diagram of systematic review.

the various physiotherapy techniques such as electrotherapy [12], strength and proprioception training [13], and aqua fitness training [14], further progress is needed identify and design a protocol for the physiotherapeutic approach in patients with hemophilic arthropathy. Conducting studies with a good methodological design that evaluate the safety and efficacy of well-defined protocols is fundamental for the generalized use of physiotherapy in patients with hemophilia [15]

The present study aims to carry out a systematic review of the treatment of physiotherapy in an approach to patients with hemophilic arthropathy.

\section{Method}

\section{Study design}

Systematic review carried out in May and June 2017.

\section{Documentary sources}

This review was prepared using the databases Science Direct, Isi Web and Medline. Haemophilia, specializing in research on patients with congenital coagulopathies, was also consulted.

\section{Search strategy}

The search strategy devised to locate the articles related to our object of study was: (haemophilia OR hemophilia) AND (physical therapy OR physiotherapy) and arthropathy) in the title, abstract and keywords.

\section{Article selection criteria}

No limit was placed on the year of publication of the articles or the language of publication in the search process.

The criteria for inclusion of the articles in this review were: published articles; describing the technique of physiotherapy used with duly identified measuring instruments; being a randomized clinical trial (RCT); and patients should be diagnosed with hemophilic arthropathy in one of the joints.

We excluded from the review those studies that were: studies in which patients followed programs of non-therapeutic exercise; and abstracts or Congress communications.

\section{Qualitative analysis of the level of scientific evidence}

In order to carry out the qualitative analysis of the level of scientific evidence of the selected articles, two scales were used: Van Tulder [16] and PEDro [17].

The Van Tulder scale analyzes the threats to the validity of randomized clinical trials based on the elements of adequacy of the random method, concealment of treatment placement, low vision and intention-to-treat analysis, using 11 items. The Physiotherapyspecific PEDro scale was developed to be used in experimental studies and provides an important source of information to support practice based on clinical evidence evaluating the internal validity and presentation of the statistical analysis of the studies, using 10 items. The presence of quality indicators scores 1 point, while no quality indicators score 0 points. 
Table 1: Characteristics of patients recruited in studies that met the inclusion criteria of this review.

\begin{tabular}{|c|c|c|c|c|c|c|c|c|}
\hline Article & n (EG) & n (CG) & Age & Type & Severity & Treatment & Inhib. & $\mathbf{H}$ \\
\hline \multirow[t]{4}{*}{ Mazloum et al. 2014} & $\mathrm{~N}_{\text {pre } 1}=13$ & $\mathrm{~N}_{\mathrm{pre}}=13$ & EG1: 33.1 (10.5) & HA: 26 & Severe: 19 & Prophylaxis: 17 & 0 & No \\
\hline & $\mathrm{N}_{\text {post1 }}=11$ & $\mathrm{~N}_{\text {post }}=9$ & EG2: 33.4 (10.5) & HB: 5 & Moderate: 12 & On demand:14 & & \\
\hline & $\mathrm{N}_{\text {pre2 }}=14$ & & CG: $33.6(9.2)$ & & & & & \\
\hline & $\mathrm{N}_{\text {post2 }}=9$ & & & & & & & \\
\hline \multirow[t]{2}{*}{ Goto et al. 2014} & $\mathrm{~N}_{\mathrm{pre1}}=19$ & $\mathrm{~N}_{\mathrm{pre}}=18$ & EG: $41.8(8.6)$ & HA: 26 & Severe: 27 & Prophylaxis: 25 & 0 & No \\
\hline & $\mathrm{N}_{\text {post1 }}=16$ & $\mathrm{~N}_{\text {post }}=16$ & CG: 43.9 (10.7) & HB: 6 & Moderate or mild: 5 & On demand: 7 & & \\
\hline \multirow[t]{2}{*}{ Al-Ghalib et al. 2014} & $\mathrm{~N}_{\text {pre1 }}=25$ & $\mathrm{~N}_{\mathrm{pre}}=25$ & EG: 38.14 (8.32) & HA: 50 & Moderate: 50 & Prophylaxis: 0 & DU & DU \\
\hline & $\mathrm{N}_{\text {post1 }}=25$ & $\mathrm{~N}_{\text {post }}=25$ & CG: 37.97 (9.15) & & & On demand: 50 & & \\
\hline \multirow[t]{2}{*}{ Cuesta-Barriuso et al. I 2014} & $\mathrm{~N}_{\text {pre } 1}=5$ & $\mathrm{~N}_{\text {pre2 }}=4$ & EG1: 37.6 (13.1) & $\mathrm{HA}: 7$ & Severe: 8 & Prophylaxis: 9 & 0 & No \\
\hline & $\mathrm{N}_{\text {post1 }}=5$ & $\mathrm{~N}_{\text {post2 }}=4$ & EG2: 33.5 (11.7) & HB: 2 & Moderate: 1 & On demand: 0 & & \\
\hline \multirow[t]{4}{*}{ Cuesta-Bariuso et al. II 2014} & $\mathrm{~N}_{\mathrm{pre} 1}=11$ & $\mathrm{~N}_{\mathrm{pre}}=10$ & EG1: 35.3 (13.06) & HA: 26 & Severe: 19 & Prophylaxis: 17 & 0 & No \\
\hline & $\mathrm{N}_{\text {post1 }}=11$ & $\mathrm{~N}_{\text {post }}=9$ & EG2: 33.4 (14.87) & HB: 5 & Moderate: 12 & On demand:14 & & \\
\hline & $\mathrm{N}_{\text {pre2 }}=10$ & & CG: 37.1 (11.59) & & & & & \\
\hline & $\mathrm{N}_{\text {post2 }}=9$ & & & & & & & \\
\hline \multirow[t]{2}{*}{ Eid et al. 2014} & $\mathrm{~N}_{\text {pre } 1}=15$ & $\mathrm{~N}_{\mathrm{pre}}=15$ & EG: 12.00 (1.36) & HA: 30 & Moderate: 30 & Prophylaxis: 30 & 0 & DU \\
\hline & $\mathrm{N}_{\text {post1 }}=15$ & $\mathrm{~N}_{\text {post }}=15$ & CG: 12.13 (1.35) & & & On demand: 0 & & \\
\hline \multirow[t]{2}{*}{ Mohamed et al. 2014} & $\mathrm{~N}_{\mathrm{pre1}}=15$ & $\mathrm{~N}_{\mathrm{pre}}=15$ & EG: 12.40 (1.37) & HA: 30 & Mild and moderate: 30 & Prophylaxis: 0 & DU & DU \\
\hline & $\mathrm{N}_{\text {post1 }}=15$ & $\mathrm{~N}_{\text {post }}=15$ & CG: 12.80 (1.39) & & & On demand: 30 & & \\
\hline \multirow[t]{2}{*}{ El-Shamy et al. 2016} & $\mathrm{~N}_{\text {pre } 1}=15$ & $\mathrm{~N}_{\mathrm{pre}}=15$ & EG: 11.55 (1.34) & HA: 30 & DU & Prophylaxis: 30 & 0 & DU \\
\hline & $\mathrm{N}_{\text {post1 }}=15$ & $\mathrm{~N}_{\text {post }}=15$ & CG: 11.43 (1.45) & & & On demand: 0 & & \\
\hline \multirow[t]{2}{*}{ Runkel et al. 2017} & $\mathrm{~N}_{\mathrm{pre} 1}=32$ & $\mathrm{~N}_{\mathrm{pre}}=32$ & EG: 41.9 (10.6) & HA: 48 & Severe: 47 & DU & 3 & DU \\
\hline & $\mathrm{N}_{\text {post1 }}=24$ & $\mathrm{~N}_{\text {post }}=28$ & CG: 40.3 (8.8) & HB: 4 & Moderate: 5 & & & \\
\hline Cuesta-Barriuso II et al. 2017 & & & & & Mild: 7 & & & \\
\hline
\end{tabular}

$\mathrm{N}_{\text {exp }}$ : Number of patients in experimental group; $\mathrm{N}_{\text {cont }}$ : Number of patients in control group; Type: Type of Hemophilia (A or B); Severity: Severity of Hemophilia (severe, moderate or mild); Treatment: Pharmacological Treatment (prophylactic or on demand); Inhib.: Inhibitor (antibodies to FVIII or FIX); H: Haemarthrosis during the treatment period; GE: Experimental Group; EG1: Experimental Group 1; EG2: Experimental Group 2; CG: Control Group; HA: Hemophilia A; HB: Hemophilia B; DU: Data Unavailable

\section{Quantitative analysis of selected studies}

An analysis was carried out to obtain the main descriptive statistics (mean and standard deviation) of the methodological variables of the treatment and of the patients recruited in the articles analyzed.

Similarly, using the Rosenthal formula [18], the effect size of the results obtained with respect to the different study variables was calculated.

\section{Results}

\section{Search results}

As a result of the search process, 183 articles were identified. In a first phase, after discarding the 116 articles repeated among the various documentary sources, the titles and abstract of the remaining 67 studies were analyzed. Finally, following the selection process, only 10 articles [19-28] met the established criteria. Figure 1 shows the flow diagram with the selection made according to the criteria described above.

\section{Description of the sample}

The control groups and the experimental groups of most of the studies represented a homogenous population sample. However, in terms of the total population included in the different publications, there is much heterogeneity. Regarding the age of the subjects of the studies, the majority are between 9 and 64 years. The homogeneity of the type and severity of hemophilia of the patients is characteristic in all the studies, the most recruited patients being those with severe and moderate hemophilia A. However, only one of the studies [27] includes patients with FVIII/ FIX (inhibitors) antibodies, prophylactic treatment being the most frequently prescribed treatment in the patients included in the eight studies selected. Table 1 shows the main characteristics of the patients included in the selected studies.

\section{Description of applied treatments}

The most frequently used technique in the selected studies is manual therapy. The development of home exercise programs and ergonomic bicycle and treadmill exercises to develop muscle strength, gait and proprioception were the most used therapeutic tools in the studies analyzed in the present review [19-21,24,25,27,28]. Joint traction (level I-II) and active and passive kinesitherapy are also used in the approach of hemophilic arthropathy $[22,23]$. 
Table 2: Methodological characteristics of the ten studies included in the review.

\begin{tabular}{|c|c|c|c|c|c|}
\hline Article & d & Variables & $\begin{array}{l}\text { Measurement } \\
\text { instruments }\end{array}$ & Treatment & Results \\
\hline $\begin{array}{l}\text { Mazloum } \\
\text { et al. } \\
2014\end{array}$ & & $\begin{array}{l}\text {-Joint pain of knee } \\
\text {-Range of motion in } \\
\text { knee }\end{array}$ & $\begin{array}{l}\text {-Visual Analogical Scale } \\
\text {-Goniometer }\end{array}$ & $\begin{array}{l}\text {-Stretching exercises, hamstring stretching (progression from } \\
\text { isometric to isotonic) and gentle stretching (EG1). } \\
\text {-Coordinated movement of lower limb in water, hamstring } \\
\text { stretching (progression from isometric to isotonic) and gentle } \\
\text { stretching (EG2). }\end{array}$ & $\begin{array}{l}\text {-Improved joint pain level } \\
\text { and knee flexion and } \\
\text { extension (EG1 and EG2). } \\
\text {-Improved pain was } \\
\text { significantly more alleviated } \\
\text { in hydrotherapy (EG2) in } \\
\text { comparison to exercise } \\
\text { therapy (EG1) }\end{array}$ \\
\hline $\begin{array}{l}\text { Goto et al. } \\
2014\end{array}$ & 8 & $\begin{array}{l}\text {-Self-efficacy } \\
\text {-Joint pain } \\
\text {-Strength of knee } \\
\text { extension } \\
\text {-Range of motion in } \\
\text { knee and ankle } \\
\text {-Dynamic standing } \\
\text { position balance } \\
\text {-Physical activity }\end{array}$ & $\begin{array}{l}\text {-modified Marcus scale } \\
\text {-Visual Analogical Scale } \\
\text {-Dynamometer } \\
\text {-Goniometer } \\
\text {-modified-Functional } \\
\text { Reach Test } \\
\text {-Accelerometer }\end{array}$ & $\begin{array}{l}\text {-Knee extension strength training: isometric exercise at a } \\
\text { long-sitting position, resistive training at sitting position, a half } \\
\text { squat with both legs at standing position and a half squat with } \\
\text { a single leg at standing position (EG and CG). } \\
\text {-Balance training ( } 3 \text { times per day): moving the body's center } \\
\text { of gravity, stepping and standing balance exercises with a } \\
\text { single leg (EG and CG) } \\
\text {-System of self-monitoring. The subjects access a server and } \\
\text { receive the feedback results of exercise over time shown in } \\
\text { graphs and } \\
\text { tables after monitoring items (EG). }\end{array}$ & $\begin{array}{l}\text {-Improved self-efficacy and } \\
\text { strength of knee extension } \\
\text { (significant in EG compared } \\
\text { with CG). } \\
\text {-Improved strength of } \\
\text { knee extension, range of } \\
\text { knee extension and ankle } \\
\text { dorsiflexion, balance and } \\
\text { physical activity (EG and } \\
\text { CG). }\end{array}$ \\
\hline $\begin{array}{l}\text { Al-Ghalib } \\
\text { et al. } \\
2014\end{array}$ & 12 & $\begin{array}{l}\text {-Hand grip strength } \\
\text {-Markers of bone } \\
\text { metabolism } \\
\text { (serum calcium and } \\
\text { parathyroid hormone) }\end{array}$ & $\begin{array}{l}\text {-Jamar hand } \\
\text { dynamometer } \\
\text {-Samples of venous } \\
\text { blood }\end{array}$ & $\begin{array}{l}\text {-Moderate intensity aerobic exercise training at } 65 \% \text { to } \\
75 \% \text { of the maximum heart rate achieved in a reference ST } \\
\text { performed according to a modified Bruce protocol (EG1). } \\
\text {-Mild intensity aerobic exercise training at } 50 \% \text { to } 60 \% \text { of the } \\
\text { maximum heart rate (EG2). }\end{array}$ & $\begin{array}{l}\text {-Improve markers of bone } \\
\text { metabolism and hand grip } \\
\text { strength (EG1). }\end{array}$ \\
\hline $\begin{array}{l}\text { Cuesta- } \\
\text { Barriuso et } \\
\text { al. I } \\
2014\end{array}$ & 6 & $\begin{array}{l}\text {-Joint pain of ankle } \\
\text {-Range of motion } \\
\text {-Proprioception } \\
\text {-Quality of life }\end{array}$ & $\begin{array}{l}\text {-Visual Analogical } \\
\text { Scale } \\
\text {-Goniometer } \\
\text {-Romberg's test } \\
\text {-A36 Hemophilia-QoL }\end{array}$ & $\begin{array}{l}\text {-Superficial thermotherapy, passive mobilizations, resisted } \\
\text { exercises, active muscle stretching, unipodal support with } \\
\text { open and closed eyes and cryotherapy (EG1). } \\
\text {-Superficial thermotherapy, joint traction I-II, active exercise, } \\
\text { passive muscle stretching, unipodal support with open and } \\
\text { closed eyes and cryotherapy (EG2). }\end{array}$ & $\begin{array}{l}\text {-Improved all ankle } \\
\text { movements (EG and CG). } \\
\text {-Improved QoL (EG). } \\
\text {-Improved ankle pain (EG). }\end{array}$ \\
\hline $\begin{array}{l}\text { Cuesta- } \\
\text { Bariuso et } \\
\text { al. II } \\
2014\end{array}$ & 12 & $\begin{array}{l}\text {-Joint pain of ankle } \\
\text {-Range of movement } \\
\text {-Muscle strength } \\
\text {-Gastrocnemius } \\
\text { circumference }\end{array}$ & $\begin{array}{l}\text {-Visual Analogical Scale } \\
\text {-Goniometer } \\
\text {-Rupture test } \\
\text {-Tape measure }\end{array}$ & $\begin{array}{l}\text {-Superficial thermotherapy, joint traction I-II, passive muscle } \\
\text { stretching, isometric and resisted exercise, unipodal support } \\
\text { with open and closed eyes and cryotherapy (EG1). } \\
\text {-Educational sessions, exercises in favor of gravity to } \\
\text { improve the ROM, isometric and isotonic exercises of } \\
\text { ankle, active exercises for mobility and pain management, } \\
\text { ankle proprioception exercises and swimming and cycling } \\
\text { technique (EG2). }\end{array}$ & $\begin{array}{l}\text {-Improved ankle pain (EG). } \\
\text {-Improved gastrocnemius } \\
\text { circumference (EG). }\end{array}$ \\
\hline $\begin{array}{l}\text { Eid et al. } \\
2014\end{array}$ & 12 & $\begin{array}{l}\text {-Bone mineral density } \\
\text {-Muscle strength } \\
\text {-Functional ability }\end{array}$ & $\begin{array}{l}\text {-Dual Energy X-ray } \\
\text { Absorptiometry } \\
\text {-Isokinetic } \\
\text { dynamometer } \\
\text {-Six Minute Walk test }\end{array}$ & $\begin{array}{l}\text {-Bicycle ergometer and resistance exercise training. } \\
\text {-Gentle stretching exercises for biceps brachii, hamstrings } \\
\text { and calf muscles, static muscle contraction for quadriceps, } \\
\text { hamstrings, anterior tibial group, calf muscles, biceps and } \\
\text { triceps, Aerobic exercise in the form of treadmill training } \\
\text { (CG). }\end{array}$ & $\begin{array}{l}\text {-Improved in bone mineral } \\
\text { density }(E G) \text {. } \\
\text {-Improved knee extensors } \\
\text { and flexors strength (EG). } \\
\text {-Improved functional ability } \\
\text { (EG and CG). }\end{array}$ \\
\hline $\begin{array}{l}\text { Mohamed } \\
\text { et al. } \\
2014\end{array}$ & 12 & $\begin{array}{l}\text {-Balance } \\
\text {-Gait parameters }\end{array}$ & $\begin{array}{l}\text {-Dynamic balance } \\
\text { test (Biodex Stability } \\
\text { System) } \\
\text {-Biodex gait trainer } \\
\text { 2TM }\end{array}$ & $\begin{array}{l}\text {-Gentle stretching exercises, isometric muscle contraction } \\
\text { and balance and gait training exercises with obstacles (EG } \\
\text { and } C G) \\
\text {-Bicycle ergometer (EG) } \\
\text {-Aerobic exercise in the form of treadmill training (CG) }\end{array}$ & $\begin{array}{l}\text {-Improved balance and gait } \\
\text { parameters (EG and } C G)\end{array}$ \\
\hline $\begin{array}{l}\text { El-Shamy } \\
\text { et al. } \\
2016\end{array}$ & 12 & $\begin{array}{l}\text {-Joint pain } \\
\text {-Functional ability } \\
\text {-Gait parameters }\end{array}$ & $\begin{array}{l}\text {-Visual Analogical Scale } \\
\text {-Six Minute Walk test } \\
\text {-GAITRite }{ }^{\circledR} \text { system }\end{array}$ & $\begin{array}{l}\text {-Hot packs, muscle stretching, strengthening exercises, } \\
\text { proprioceptive training, balance and gait training (EG and } \\
\text { CG) } \\
\text {-Pulsed high intensity laser therapy: dose of } 1500 \mathrm{~J} \text { for both } \\
\text { knees ( } 750 \mathrm{~J} \text { for each knee) administered throughout three } \\
\text { phases (EG) }\end{array}$ & $\begin{array}{l}\text {-Improved Joint pain (EG) } \\
\text {-Improved functional ability } \\
(E G) \\
\text {-Improved gait parameters } \\
(E G)\end{array}$ \\
\hline $\begin{array}{l}\text { Runkel } \\
\text { et al. } 2017\end{array}$ & 24 & $\begin{array}{l}\text {-Subjective physical } \\
\text { performance } \\
\text {-Perception of generic } \\
\text { quality of life } \\
\text {-Perception of specific } \\
\text { quality of life }\end{array}$ & $\begin{array}{l}\text {-HEP-Test-Q } \\
\text {-SF-36 Health Survey } \\
\text {-Haem-A-QoL }\end{array}$ & $\begin{array}{l}\text {-A training plan for one patient usually consisted of 5-9 } \\
\text { exercises (e.g. cable pull, leg press), which were selected out } \\
\text { of an exercise catalogue of } 30 \text { practices regarding strength } \\
\text { and coordination. Mobility and endurance were adopted } \\
\text { individually. To get accustomed to the training, it was } \\
\text { prescribed to begin with } 10-30 \% \text { of the maximum power in } \\
\text { the first } 3-4 \text { weeks, followed by } 30-50 \% \text { and finally } 50-70 \% \\
\text { in the last } 4-6 \text { months. In addition, the norm was three rates } \\
\text { of } 15 \text { repetitions (EG). }\end{array}$ & $\begin{array}{l}\text {-Improved of subjective } \\
\text { physical performance (EG) } \\
\text {-Improved some domains of } \\
\text { HR-QoL (EG). }\end{array}$ \\
\hline $\begin{array}{l}\text { Cuesta- } \\
\text { Barriuso et al. } \\
2017\end{array}$ & 15 & $\begin{array}{l}\text {-Joint status } \\
\text {-Joint pain } \\
\text {-IIIness behavior } \\
\text {-Perception of quality } \\
\text { of life }\end{array}$ & $\begin{array}{l}\text {-Gilbert score } \\
\text {-Visual Analogical Scale } \\
\text {-Illness Behavior } \\
\text { Questionnaire } \\
\text {-A36 Hemophilia-QoL }\end{array}$ & $\begin{array}{l}\text {-Educational sessions, muscle stretching exercises of } \\
\text { upper and lower limbs, isometric exercises of quadriceps, } \\
\text { hamstrings, biceps, triceps, and calves, active exercises for } \\
\text { mobility and pain management, proprioceptive exercises } \\
\text { on } 1 \text { leg with visual support and recommended sports in } \\
\text { hemophilia (EG) }\end{array}$ & $\begin{array}{l}\text {-Improved Joint pain (EG) } \\
\text {-Improved some variables of } \\
\text { illness behavior }(E G) \\
\text {-Improved some variables of } \\
\text { quality of life }(E G)\end{array}$ \\
\hline
\end{tabular}

D: Type of Study; d: duration of the treatment (weeks); RCT: Randomized Clinical Trial; Variables: Dependent Variables; ROM: Range of Movement; Treatment: characteristic of the treatment of the study; EG: Experimental Group 1; EG2: Experimental Group 2; CG: Control Group. 
Table 3: Van Tulder and PEDro Scale: qualitative analysis of the level of scientific evidence of the selected studies.

\begin{tabular}{|c|c|c|c|c|c|c|c|c|c|c|c|}
\hline Scale & Items & $\begin{array}{c}\text { Mazloum } \\
2014\end{array}$ & $\begin{array}{l}\text { Goto } \\
2014\end{array}$ & \begin{tabular}{|c|} 
Al- \\
Ghalib \\
2014 \\
\end{tabular} & $\begin{array}{l}\text { Cuesta- } \\
\text { Barriuso I } \\
2014\end{array}$ & \begin{tabular}{|c|} 
Cuesta-Barriuso \\
II \\
2014 \\
\end{tabular} & $\begin{array}{c}\text { Eid } \\
2014\end{array}$ & $\begin{array}{c}\text { Mohamed } \\
2014\end{array}$ & \begin{tabular}{|c} 
El- \\
Shamy \\
2016
\end{tabular} & $\begin{array}{c}\text { Runkel } \\
2017\end{array}$ & $\begin{array}{c}\text { Cuesta- } \\
\text { Barriuso } \\
2017 \\
\end{array}$ \\
\hline \multirow{12}{*}{$\begin{array}{l}\text { Van } \\
\text { Tulder }\end{array}$} & Was the method of randomization adequate? & 0 & 1 & 0 & 0 & 1 & 0 & 1 & 1 & 0 & 1 \\
\hline & Was the treatment allocation concealed? & 1 & 1 & 1 & 1 & 1 & 1 & 1 & 1 & 1 & 1 \\
\hline & Were the groups similar at baseline? & 1 & 1 & 1 & 1 & 1 & 1 & 1 & 1 & 1 & 1 \\
\hline & Was the patient blinded to the intervention? & 0 & 0 & 0 & 0 & 0 & 0 & 0 & 1 & 0 & 0 \\
\hline & Was the care provider blinded to the intervention? & 0 & 0 & 0 & 0 & 0 & 0 & 0 & 0 & 0 & 0 \\
\hline & $\begin{array}{l}\text { Was the outcome assessor blinded to the } \\
\text { intervention? }\end{array}$ & 0 & 0 & 0 & 1 & 1 & 0 & 0 & 0 & 0 & 1 \\
\hline & Were co-interventions avoided or similar? & 1 & 1 & 1 & 1 & 1 & 1 & 1 & 1 & 1 & 1 \\
\hline & Was the compliance acceptable in all groups? & 1 & 1 & 1 & 1 & 1 & 1 & 1 & 1 & 1 & 1 \\
\hline & Was the drop-out rate described and acceptable? & 1 & 1 & 1 & 1 & 1 & 1 & 1 & 1 & 0 & 1 \\
\hline & $\begin{array}{l}\text { Was the timing of the outcome assessment in all } \\
\text { groups similar? }\end{array}$ & 1 & 1 & 1 & 1 & 1 & 1 & 1 & 1 & 1 & 1 \\
\hline & $\begin{array}{l}\text { Did the analysis include an intention-to-treat } \\
\text { analysis? }\end{array}$ & 0 & 0 & 1 & 1 & 1 & 1 & 1 & 1 & 0 & 1 \\
\hline & Total scale & 6 & 7 & 7 & 8 & 9 & 7 & 8 & 9 & 5 & 9 \\
\hline \multirow{11}{*}{ PEDro } & Eligibility criteria were specified $^{*}$ & 1 & 1 & 1 & 1 & 1 & 1 & 1 & 0 & 0 & 1 \\
\hline & Subjects were randomly allocated to groups & 1 & 1 & 1 & 1 & 1 & 1 & 1 & 1 & 1 & 1 \\
\hline & Allocation was concealed & 0 & 1 & 0 & 0 & 1 & 0 & 1 & 1 & 0 & 1 \\
\hline & The groups were similar at baseline & 1 & 1 & 1 & 1 & 1 & 1 & 1 & 1 & 1 & 1 \\
\hline & There was blinding of all subjects & 0 & 0 & 0 & 0 & 0 & 0 & 0 & 1 & 0 & 0 \\
\hline & $\begin{array}{l}\text { There was blinding of all therapists who } \\
\text { administered the therapy }\end{array}$ & 0 & 0 & 0 & 0 & 0 & 0 & 0 & 0 & 0 & 0 \\
\hline & $\begin{array}{l}\text { There was blinding of all assessors who measured } \\
\text { key outcome }\end{array}$ & 0 & 0 & 0 & 1 & 1 & 0 & 0 & 0 & 0 & 1 \\
\hline & $\begin{array}{l}\text { Measures were obtained from more than } 85 \% \text { of } \\
\text { the subjects allocated }\end{array}$ & 1 & 1 & 1 & 1 & 1 & 1 & 1 & 1 & 0 & 1 \\
\hline & $\begin{array}{l}\text { All subjects for whom outcome measures were } \\
\text { available outcome }\end{array}$ & 1 & 1 & 1 & 1 & 1 & 1 & 1 & 1 & 1 & 1 \\
\hline & $\begin{array}{l}\text { The results of between-group statistical comparison } \\
\text { are reported }\end{array}$ & 1 & 1 & 1 & 1 & 0 & 1 & 1 & 1 & 1 & 1 \\
\hline & Total scale & 5 & 6 & 6 & 6 & 6 & 5 & 6 & 7 & 4 & 7 \\
\hline
\end{tabular}

*Item not evaluable

Two articles $[23,28]$ include an educational physiotherapy program in adult patients with hemophilia, and finally one article studies the safety and efficacy of a laser electrotherapy technique in hemophilia [26]. Table 2 details the methodological characteristics of the treatments carried out in the studies under review, as well as the results obtained in each one.

No adverse effects or complications have been found as a result of the administration of physiotherapy techniques. This suggests the safety of these interventions from the hemorrhagic point of view, and may help to identify a better efficacy and adherence to the treatment in these patients.

\section{Qualitative analysis of the level of scientific evidence}

The level of evidence of the studies obtained through the Van Tulder scale shows us that three studies $[23,26,28]$ score a maximum of 9 out of 11 points. Blinding of the therapist and the patient or rater are the only items in which these articles did not achieve a positive score. On the other hand, two articles scored 8 points [22,25], the failure to describe the method of randomization being the main methodological deficiency. Three studies $[20,21,24]$ scored 7 points, while one article scored 6 points [19], and only one [27] 5 points. This qualitative analysis presents medium-high scores due to proper randomization, the simple blind design and low experimental death, among other variables measured in the studies.

Regarding the analysis performed using the PEDro scale, we also obtained a maximum score of 7 points, in two studies [26,28], in which only the therapist's, and the patient's or rater's, blinding is the negative item. Similarly, five articles [20-23,25] scored 6 points out of 9 , mainly as a result from not describing the method of randomization and comparison between groups. Finally, two articles $[19,24]$ scored 5 points, the main methodological deficiencies being blinding and randomization, while another article only reached a score of 4 points [27]. Based on the scores performed with the PEDro scale, we are able to conclude overall the medium-high methodological quality of the selected articles. The evaluation of the level of scientific evidence of the selected articles is shown in Table 4.

\section{Quantitative analysis of selected studies}

The selected studies have been quantitatively analyzed, valuing the main descriptive statistics regarding the sample and the physiotherapy interventions performed. The homogeneity in terms of duration of treatments with a mean of 11.70 weeks (range: 4-24) is noteworthy. With regard to the treatment intensity, the studies had a mean of 3.16 hours per week, with a range of 2-7.5 hours per week. 
Table 4: Sample and treatment characteristics of selected articles, and their quantitative analysis.

\begin{tabular}{|c|c|c|c|c|c|}
\hline Moderating variables & k & Min. & Max. & Mean & SD \\
\hline \multicolumn{6}{|l|}{ Treatment variables } \\
\hline Duration (weeks) & 10 & 4 & 24 & 11.70 & 5.45 \\
\hline Intensity (hours/week) & 9 & 2 & 7.5 & 3.16 & 1.69 \\
\hline Magnitude (hours/treatment) & 9 & 12 & 112.5 & 40.5 & 32.41 \\
\hline \multicolumn{6}{|l|}{ Subject variables } \\
\hline Age (years) & 10 & 9 & 64 & 29.35 & 12.42 \\
\hline \multicolumn{6}{|l|}{ Methodological variables } \\
\hline SS of the experimental group, at baseline & 10 & 5 & 32 & 18.60 & 8.38 \\
\hline SS of the experimental group, at post treatment & 10 & 5 & 27 & 17.20 & 6.89 \\
\hline SS of the experimental group, at follow-up & 3 & 5 & 20 & 11.67 & 7.63 \\
\hline SS of the control group, at baseline & 10 & 4 & 32 & 15.80 & 7.91 \\
\hline SS of the control group, at post treatment & 10 & 4 & 28 & 15.00 & 7.11 \\
\hline SS of the control group, at follow-up & 3 & 4 & 10 & 7.67 & 3.21 \\
\hline Differential mortality in post treatment assessment (\%) & 10 & 0 & 18.7 & 4.5 & 6.7 \\
\hline Differential mortality in follow-up assessment (\%) & 3 & 0 & 0 & 0 & 0 \\
\hline
\end{tabular}

SS: Sample Size; \%: Percentage; k: Number of Articles; Min: Minimum Range; Max: Maximum Range; SD: Standard Deviation

Thus, the magnitude in terms of total hours of treatment was 40.5 hours on average. As for age, the population of the selected studies $(\mathrm{n}=344)$ had a mean age of 29.35 years, widely ranging from 9 to 64 years.

\section{Methodological variables}

With regard to sample size, experimental death in both experimental and control groups, in the different evaluations (pretreatment, post-treatment and follow-up), indicate a very low number of dropouts during the interventions.

As for the experimental mortality data, all articles contribute data after the treatment period, presenting an average percentage of $4 \%$ of dropouts due to different causes. On the other hand, the 3 articles that assessed post-follow-up $[22,23,28]$ showed that none of the patients with hemophilia dropped out in this last assessment. The evaluation of the quantitative analysis of the selected studies is shown in Table 4.

\section{Results of effect size calculation}

The effect size, measured as the mean difference between pretreatment standard deviation, yielded varying results depending on the study analyzed.

According to this statistical analysis, the treatment with a large effect size $(\mathrm{d}>0.8)$, and thus a greater magnitude of the effect of its results, is that carried out by El-Shamy, et al. [26] regarding improvement of knee pain, functionality and gait. Also noteworthy is the intervention based on balance, gait and ergonomic bicycle isometric exercises, carried out by Eid, et al. [24] and Mohamed, et al. [25].

Although the use of a sports therapy program and manual and educational therapy showed significant improvements, they showed mean effect size results $(\mathrm{d}>0.5)$, the ankle pain variable providing stronger results, followed by proprioception and quality of life $[22,23,27,28]$. Finally, it should be noted that the use of monitored home exercises [20] presents a high effect size in the improvement of knee extension strength $(\mathrm{d}=1.02)$. The remaining results provided a low effect size $(\mathrm{d}<0.5)$, which reduces the weight of the results, and therefore their efficacy, in the clinical improvement of patients with hemophilic arthropathy. Table 5 shows the results of the effect size calculation of the selected studies.

\section{Discussion}

The aim of this review is to evaluate the efficacy of physiotherapy in the treatment of patients with hemophilic arthropathy. Following a search carried out in the various documentary sources, ten randomized clinical trials were selected. In the reviewed studies, the effectiveness of different physiotherapy techniques was analyzed in the approach to the main clinical manifestations of hemophilic arthropathy (chronic pain, reduced range of motion, loss of muscle strength, and impaired gait and proprioception).

The safety of physiotherapy interventions in patients with hemophilia is an essential aspect. The literature discloses clinical studies in which, when administering physiotherapy interventions, the frequency of bleeding was reduced $[29,30]$. In this regard, although only three studies clearly indicate that none of the patients suffered bleeding episodes $[20,22,23]$, the remaining studies report no bleeding complications.

The chronic pain associated with hemophilic arthropathy is one of the major clinical manifestations reported by patients, and one of the leading causes of disability [31]. The improvement of this variable in most of the studies analyzed in this review is a good prognostic factor for the use of the techniques described in standard clinical practice.

Hemophiliac arthropathy in the lower limb joints (knee and ankles), causes significant alterations in gait and function $[32,33]$. The effectiveness of the interventions analyzed, regarding the improvement of these two variables allows us to support the suitability of applying, within the usual clinical protocol, the guidelines described in the articles included in this review. 
Table 5: Calculation of the effect size of the treatments studied.

\begin{tabular}{|c|c|c|c|c|c|}
\hline Article & Variable & M (SD) pre & $M(S D)$ post & Sig. & ES \\
\hline $\begin{array}{l}\text { Mazloum et al. } \\
2014\end{array}$ & $\begin{array}{l}\text { Joint pain of knee (EG1) } \\
\text { Joint pain of knee (EG2) } \\
\text { Flexion in knee (EG1) } \\
\text { Flexion in knee (EG2) } \\
\text { Extension in knee (EG1) } \\
\text { Extension in knee (EG2) }\end{array}$ & $\begin{array}{c}6.6 .(1.3) \\
6.9(1.3) \\
102.8(24.0) \\
111.5(14.4) \\
-10.6(5.2) \\
-9.1(5.4)\end{array}$ & $\begin{array}{c}5.7(1.4) \\
5.2(1.3) \\
110.0(24.0) \\
118.5(13.4) \\
-8.7(5.0) \\
-7.1(4.9)\end{array}$ & $\begin{array}{l}p<0.001 \\
p<0.001 \\
p<0.001 \\
p<0.001 \\
p<0.001 \\
p<0.001\end{array}$ & $\begin{array}{r}-0.69 \\
-1.30 \\
0.30 \\
0.48 \\
0.36 \\
0.37\end{array}$ \\
\hline \multirow{6}{*}{ Goto et al. 2014} & Self-efficacy for exercise (points) & $16.0(4.8)$ & $17.9(2.9)$ & $p=.049$ & 0.39 \\
\hline & Joint pain & $14.2(11.4)$ & $16.7(15.3)$ & $p=.493$ & 0.21 \\
\hline & Strength of knee extension & $1.03(0.4)$ & $1.44(0.7)$ & $p=.000$ & 1.02 \\
\hline & Range of knee extension & $-6.9(7.3)$ & $-2.5(3.7)$ & $p=.000$ & 0.60 \\
\hline & Range of ankle dorsiflexion & $-5.0(25.4)$ & $0(21.5)$ & $p=.004$ & 0.19 \\
\hline & Dynamic standing position balance & $29.6(8.2)$ & $34.7(8.8)$ & $p=.023$ & 0.62 \\
\hline $\begin{array}{l}\text { Al-Ghalib et al. } \\
2014\end{array}$ & $\begin{array}{l}\text { Hand grip strength (EG1) } \\
\text { Hand grip strength (EG2) } \\
\text { Serum calcium (EG1) } \\
\text { Serum calcium (EG2) } \\
\text { Parathyroid hormone (EG1) } \\
\text { Parathyroid hormone (EG2) }\end{array}$ & $\begin{array}{c}138.45(8.61) \\
134.98(7.96) \\
8.26(1.47) \\
8.14(1.52) \\
14.91(2.85) \\
14.63(2.97)\end{array}$ & $\begin{array}{c}172.74(7.78) \\
155.24(7.18) \\
10.91(1.36) \\
9.37(1.42) \\
11.52(2.61) \\
13.12(2.75) \\
\end{array}$ & $\begin{array}{l}p<0.001 \\
p<0.001 \\
p<0.001 \\
p<0.001 \\
p<0.001 \\
p<0.001\end{array}$ & $\begin{array}{r}3.98 \\
2.54 \\
1.80 \\
0.80 \\
-1.18 \\
-0.50\end{array}$ \\
\hline \multirow{12}{*}{$\begin{array}{l}\text { Cuesta-Barriuso I } \\
\text { et al. } 2014\end{array}$} & Plantar flexion (EG1) & $38.3(8.3)$ & $40.4(10.2)$ & $p=.380$ & 0.25 \\
\hline & Plantar flexion (EG2) & $32.0(14.5)$ & $34.8(11.4)$ & $p=.100$ & 0.19 \\
\hline & Dorsal flexion (EG1) & $8.5(6.5)$ & $8.0(6.2)$ & $p=.680$ & -0.07 \\
\hline & Dorsal flexion (EG2) & $3.5(3.7)$ & $4.8(4.7)$ & $p=.100$ & 0.34 \\
\hline & Ankle pain (EG1) & $3.6(2.1)$ & $2.6(1.8)$ & $p=.010$ & -0.48 \\
\hline & Ankle pain (EG2) & $5.6(2.1)$ & $5.0(2.0)$ & $p=.014$ & -0.30 \\
\hline & Romberg test, open eyes (EG1) & $0.7(0.4)$ & $0.6(0.1)$ & $p=.470$ & 0.36 \\
\hline & Romberg test, open eyes (EG2) & $0.7(0.2)$ & $0.5(0.2)$ & $p=.350$ & -0.63 \\
\hline & Romberg test, closed eyes (EG1) & $0.9(0.5)$ & $1.0(0.3)$ & $p=.450$ & 0.13 \\
\hline & Romberg test, closed eyes (EG2) & $0.7(0.3)$ & $0.7(0.2)$ & $p=.720$ & -0.21 \\
\hline & Limits test (EG1) & $73.8(42.4)$ & $59.8(21.3)$ & $p=.060$ & -0.33 \\
\hline & Limits test (EG2) & $41.0(4.3)$ & $38.8(6.7)$ & $p=.500$ & -0.50 \\
\hline \multirow{10}{*}{$\begin{array}{c}\text { Cuesta-Barriuso II } \\
\text { et al. } 2014\end{array}$} & Muscle strength of gastrocnemius (EG1) & $0.12(0.22)$ & $0.05(0.15)$ & $p=.08$ & -0.33 \\
\hline & Muscle strength of gastrocnemius (EG2) & $0.15(0.37)$ & $0.05(0.15)$ & $p=.10$ & -0.28 \\
\hline & Gastrocnemius muscle circumference (EG1) & $34.52(2.33)$ & $34.95(2.59)$ & $p=.00$ & 0.18 \\
\hline & Gastrocnemius muscle circumference (EG2) & $33.87(4.68)$ & $34.28(4.96)$ & $p=.07$ & 0.08 \\
\hline & Plantar flexion (EG1) & $38.35(8.35)$ & $40.45(10.21)$ & $p=.38$ & 0.25 \\
\hline & Plantar flexion (EG2) & $32.0(14.51)$ & $34.84(11.40)$ & $\mathrm{p}=.10$ & 0.19 \\
\hline & Dorsal flexion (EG1) & $8.55(6.58)$ & $8.05(6.27)$ & $p=.68$ & -0.07 \\
\hline & Dorsal flexion (EG2) & $3.58(3.79)$ & $4.89(4.70)$ & $p=.10$ & 0.34 \\
\hline & Ankle pain (EG1) & $2.95(2.38)$ & $1.10(1.81)$ & $p=.00$ & -0.77 \\
\hline & Ankle pain (EG2) & $0.84(1.42)$ & $0.44(0.83)$ & $p=.10$ & -0.27 \\
\hline \multirow{6}{*}{$\begin{array}{l}\text { Eid et al. } \\
2014\end{array}$} & Femoral neck bone mineral density & $0.59(0.17)$ & $0.86(0.12)$ & $p=.0001$ & 1.58 \\
\hline & Proximal tibia bone mineral density & $0.58(0.1)$ & $0.74(0.1)$ & $p=.0001$ & 1.60 \\
\hline & Distal tibia bone mineral density & $0.37(0.08)$ & $0.54(0.1)$ & $p=.0001$ & 2.12 \\
\hline & Knee extensors, isokinetic strength & $51.2(14.13)$ & $70.22(14.43)$ & $p=.0001$ & 1.34 \\
\hline & Knee flexors, isokinetic strength & $22.32(8.92)$ & $33.31(8.67)$ & $p=.0001$ & 1.23 \\
\hline & Functional ability & $274.66(36.02)$ & $301.66(40.86)$ & $p=.0001$ & 0.74 \\
\hline \multirow{6}{*}{$\begin{array}{c}\text { Mohamed et al. } \\
2014\end{array}$} & Overall stability index & $2.07(0.24)$ & $1.69(0.24)$ & $p=.01$ & -1.58 \\
\hline & Anterior-posterior stability index & $2.03(0.35)$ & $1.60(0.32)$ & $p=.01$ & -1.22 \\
\hline & Medio-lateral stability index & $1.41(0.32)$ & $1.05(0.24)$ & $\mathrm{p}=.01$ & -0.28 \\
\hline & Time on each foot & $41.83(1.86)$ & $43.43(1.78)$ & $p=.01$ & 0.86 \\
\hline & Average step length & $0.34(0.04)$ & $0.39(0.03)$ & $p=.01$ & 1.25 \\
\hline & Average step cycle & $0.63(0.68)$ & $0.68(0.06)$ & $p=.01$ & 0.07 \\
\hline
\end{tabular}




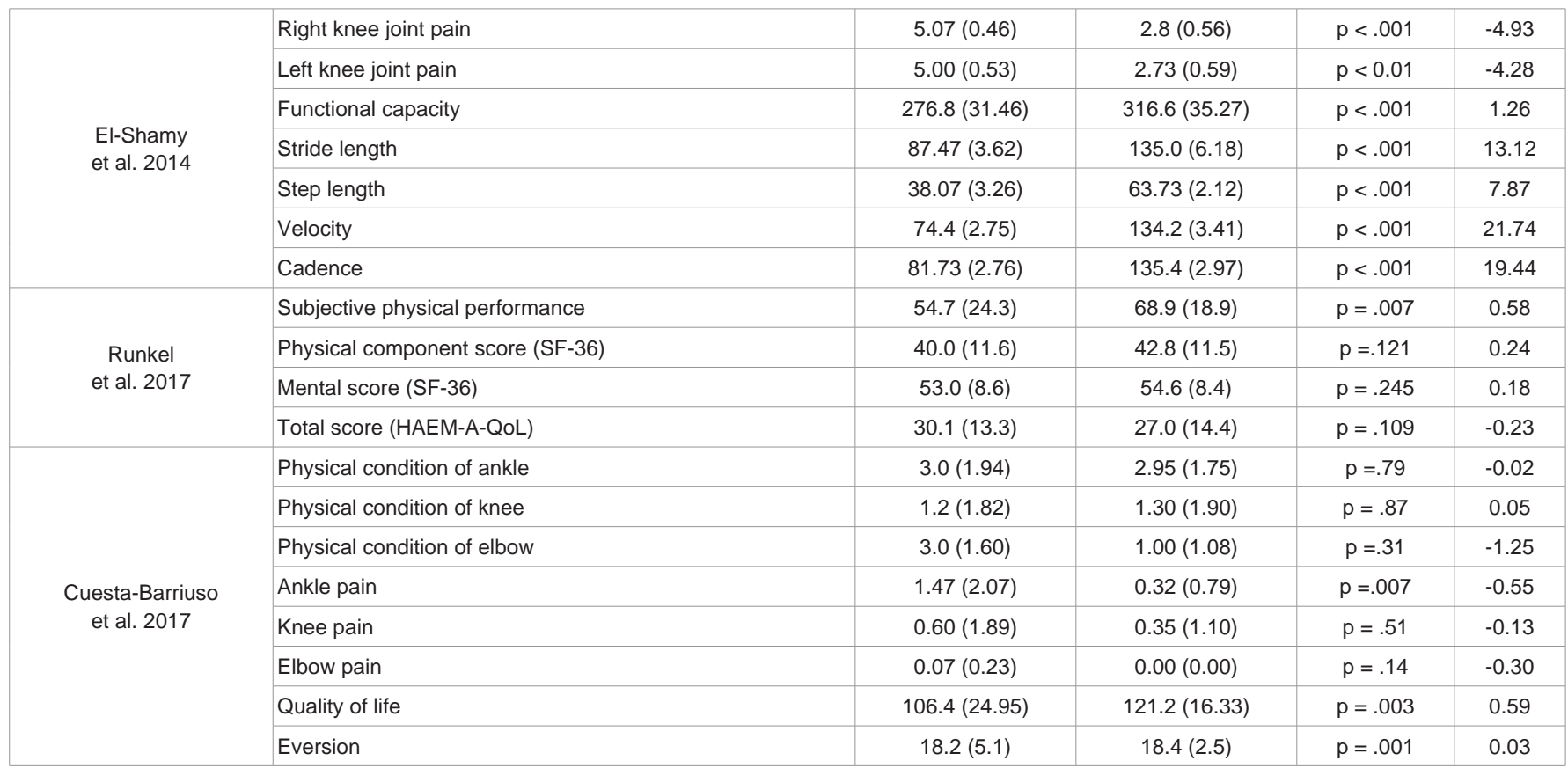

M(SD)pre: Mean (standard deviation) at baseline; M(SD)post: Mean (standard deviation) posttreatment; Sig: Signification; ES: Effect Size; EG1: Experimental Group 1; EG2: Experimental Group 2.

Although muscle strength is one of the most analyzed and studied clinical variables in patients with hemophilia [34,35], there are few randomized clinical studies that have analyzed the effectiveness of different physiotherapy techniques to improve this variable. Despite the short duration of the studies analyzed, the improvement observed may be useful in implementing protocols for improving muscular strength in patients with hemophilia, both at the hospital and at home.

An aspect that stands out in all the studies is the low dropout rate. The patient's involvement in a physiotherapy intervention and their adherence to it is an important success factor that must be encouraged. In the same way that efforts are made to implement adherence to pharmacological treatment, greater scientific evidence is needed to demonstrate the safety and efficacy of these techniques [36]. Reducing the fear of developing bleeding as a result of a physical therapy intervention together with clinical improvement will allow a greater adherence in these patients. Similarly, only one study [27] has included patients with hemophilia and inhibitors. Heijnen [37] pointed out that the administration of a physiotherapy program in these patients should be carefully protocolized, taking into account that any bleeding should be treated with ice, rest or immobilization. However, at present, the good results obtained in the prevention and treatment of bleeding with licensed derivation agents such as APCC recombinant factor VIIa and, not to mention the new still unlicensed products (emicizumab and fiturisan) allow the application of physiotherapy techniques with lower risk for these patients.

The development of typical clinical manifestations associated with hemophilic arthropathy may lead to a decrease in physical capacity and a poorer perception of quality of life [36]. Among the studies analyzed in this study, three articles $[22,27,28]$ have noted how, following a physiotherapy intervention, the quality of life of patients with hemophilia, among other dependent variables, improved.

\section{Qualitative analysis of the level of scientific evidence}

Despite the small number of randomized clinical studies analyzed, the methodological quality analysis with the Van Tulder and PEDro scales was positive. Previous reviews $[15,38]$ indicated the need to implement more ambitious methodological criteria in the development of physiotherapy studies in patients with hemophilia. The implementation of studies that include blinding systems, with a good dropout rate, and statistical analyzes according to the scientific model, support the evidence of the results obtained in each of the articles under study. Although the implementation of a broader scientific model that supports the safety and efficacy of many physiotherapy techniques in hemophilia patients is still necessary, a qualitative analysis of the level of scientific evidence offers encouraging results.

\section{Limits of the review}

The description of the main clinical data of the patients included in the different studies (type of treatment and hemophilia, and degree of arthropathies and their location, mainly) raised doubts during the data coding process. Likewise, the lack of information regarding some moderating variables (model of random sample allocation, blinding and the method of application of treatment) limited the possibilities of obtaining detailed results. Although most studies have been published in the last decade, the number of studies meeting the selection criteria is low, thus reducing the weight of the results of this review.

\section{Implications for clinical practice}

If we consider the physiotherapy techniques applied to patients with hemophilia, we note how neither complex nor expensive instruments of measurement and intervention are used. This fact may favor, together with safety in terms of absence of bleeding, the application of the interventions performed in the studies analyzed to the general population of patients with hemophilia. 
The application of any physiotherapy intervention in patients with hemophilia should combine several aspects. Safety and efficacy are two indivisible characteristics to favor both the administration of physiotherapy treatments in a continuous way and based on solid scientific evidence, such as the adherence to these interventions.

\section{Recommendations for future studies}

The consolidation of scientific evidence is a necessary and fundamental factor in the implementation of physiotherapy treatments in patients with hemophilia. Most physiotherapeutic techniques are contraindicated in patients with hemophilia. However, this criterion is based essentially on the ignorance, fear and caution of physiotherapists, rather than on scientific criteria. Therefore, through the design of randomized clinical studies duly formulated and designed, studies on physiotherapy in hemophilia should be implemented to assess the safety and efficacy of different physiotherapy techniques in these patients.

The development of multicenter studies and a larger sample of patients with hemophilia would help to achieve more consolidated results, which will help to generalize the results obtained. Likewise, blinding of raters, the use of reliable measuring instruments and the establishment of follow-up periods after the intervention would improve the methodological quality of the future studies to be carried out.

\section{Conclusion}

This systematic review suggests that physiotherapy interventions through manual therapy, stretching, muscle strength protocols and cycling exercises improve pain perception, functionality, and proprioception and muscle strength in patients with hemophilic arthropathy. Educational physiotherapy interventions along with home exercises improve joint pain, quality of life and perception of disease.

The development of the physiotherapy techniques described in this review has not been noted to cause bleeding as a result of their application in patients with hemophilia.

Further randomized clinical studies are needed to confirm the results observed and, in the same way, to increase the scientific evidence regarding the use of physiotherapy in hemophilia.

\section{References}

1. Santos A. Genetic and immunologic aspects related to the development of inhibitors in haemophilia A and B. Campina 2011; 189:1-189.

2. Lissauer T, Clayden G. Illustrated textbook of paediatrics. 4th ed. Toronto: Elsevier. 2007.

3. Gringeri A, Ewenstein B, Reininger A. The burden of bleeding in haemophilia: is one bleed too many? Haemophilia. 2014; 20: 459-463.

4. Gomis M, Querol F, Gallach JE, González LM, Aznar JA. Exercise and sport in the treatment of haemophilic patients: a systematic review. Haemophilia. 2009; 15: 43-54.

5. Rodriguez-Merchán EC. Prevention of the musculoskeletal complications of hemophilia. Adv Prev Med 2012; 2012: 201271.

6. Rodriguez-Merchán EC. Effects of hemophilia on articulations of children and adults. Clin Orthop. 1996; 7-3.

7. Bolton-Maggs PH, Pasi KJ. Haemophilias A and B. Lancet. 2003; 361: 18011809.
8. Manco-Johnson MJ, Abshire TC, Shapiro AD, Riske B, Hacker MR, Kilcoyne $\mathrm{R}$, et al. Prophylaxis versus episodic treatment to prevent joint disease in boys with severe hemophilia. N Engl J Med. 2007; 535-544.

9. Isarangkura P. Haemophilia care in the developing world: benchmarking for excellence. Haemophilia. 2002; 8: 205-210.

10. Rodríguez-Merchán EC, Jiménez-Yuste $\mathrm{V}$, Aznar JA, Hedner U, Knobe $\mathrm{K}$, Lee CA. Joint protection in haemophilia. Haemophilia. 2011; 17: 1-23.

11. Auerswald G, Dolan G, Duffy A, Hermans C, Jiménez-Yuste V, Ljung R, et al. Pain and pain management in haemophilia. Blood Coagulation and Fibrinolysis. 2016; 27: 845-854.

12. Gomis M, González LM, Querol F, Gallach JE, Toca-Herrera JL. Effects of electrical stimulation on muscle trophism in patients with hemophilic arthropathy. Arch Phys Med Rehabil. 2009;90:1924-30.

13. Groen WG, den Uijl IEM, van der Net J, Grobbee DE, de Groot G, Fischer K Protected by nature? Effects of strenuous physical exercise on FVIII activity in moderate and mild haemophilia A patients: a pilot study. Haemophilia. 2013; 19: 519-523.

14. Vallejo L1, Pardo A, Gomis M, Gallach JE, Pérez S, Querol F. Influence of aquatic training on the motor performance of patients with haemophilic arthropathy. Haemophilia. 2010; 16: 155-161

15. Schafer GS, Valderramas S, Gomes AR, Budib MB, Wolff ALP, Ramos ATT. Physical exercise, pain and musculoskeletal function in patients with haemophilia: a systematic review. Haemophilia. 2016; 22: 119-129.

16. Van Tulder M, Furlan A, Bombardier C, Bouter L. Editorial Board of the Cochrane Collaboration Back Review Group. Updated method guidelines for systematic reviews in the cochrane collaboration back review group. Spine. 2003; 28: 1290-1299.

17. Maher CG, Sherrington C, Herbert RD, Moseley AM, Elkins M. Reliability of the PEDro scale for rating quality of randomized controlled trials. Phys Ther. 2003; 83713-721.

18. Rosenthal R. Meta-Analytic Procedures for Social Research, Sage, Beverly Hills, Calif, USA. 1984

19. Mazloum V, Rahnama N, Khayambashi K. Effects of Therapeutic Exercise and Hydrotherapy on Pain Severity and Knee Range of Motion in Patients with Hemophilia: A Randomized Controlled Trial. Int J Prev Med. 2014; 5: 83-88.

20. Goto M, Takedani H, Haga N, Kubota M, Ishiyama M, Ito S. Self-monitoring has potential for home exercise programmes in patients with haemophilia. Haemophilia 2014; 20: 121-127.

21. Al-Ghalib F, Hussien O, Mahmoud S, Mohamed E. Impact of Mild versus Moderate Intensity Aerobic Walking Exercise Training on Markers of Bone Metabolism and Hand Grip Strength in Moderate Hemophilic A Patients. Afr Health sci. 2014; 14: 11-16.

22. Cuesta-Barriuso R, Gómez-Conesa A, López-Pina JA. Manual therapy in the treatment of ankle hemophilic arthropathy. A randomized pilot study. Physiother Theory Pract. 2014; 30: 534-9.

23. Cuesta-Barriuso R, Gómez-Conesa A, López-Pina JA. Effectiveness of two modalities of physiotherapy in the treatment of haemophilic arthropathy of the ankle: a randomized pilot study. Haemophilia. 2014; 20: 71-78.

24. Eid M, Ibrahim M, Aly S. Effect of resistance and aerobic exercises on bone mineral density, muscle strength and functional ability in children with hemophilia. The Egyptian Journal of Medical Human Genetics 2014; 15:13914.

25. Mohamed R, El-Aziz A. Bicycle ergometer versus treadmill on balance and gait parameters in children with hemophilia. The Egyptian Journal of Medical Human Genetics. 2015; 16: 181-187.

26. El-Shamy SM, Mohamed Abdelaal AAM. Efficacy of pulsed high-intensity laser therapy on pain, functional capacity, and gait in children with haemophilic arthropathy. Disabil Rehabil. 2016. 1-7.

27. Runkel B, Von Mackensen S, Hilberg T. RCT-subjective physical performance and quality of life after a 6-month programmed sports therapy (PST) in 
patients with haemophilia. Haemophilia. 2017; 23: 144-151.

28. Cuesta-Barriuso R, Torres-Ortuño A, Nieto-Munuera J, López-Pina JA Effectiveness of an Educational Physiotherapy and Therapeutic Exercise Program in Adult Patients with Hemophilia: A Randomized Controlled Trial. Archives of Physical Medicine and Rehabilitation. 2017; 98: 841-848.

29. Pelletier R, Findley TW, Gemma SA. Isometric exercise for an individual with hemophilic arthropathy. Phys Ther. 1987; 67: 1359-1364.

30. Hilberg T, Herbsleb M, Gabriel HHW, Jeschke D, Schramm W. Proprioception and isometric muscular strength in haemophilic subjects. Haemophilia. 2001 7: 582-588.

31. Stephensen D, Rodriguez-Merchan EC. Orthopaedic co-morbidities in the elderly haemophilia population: a review. Haemophilia. 2013; 19: 166-73.

32. Lobet S, Lambert C, Hermans C. Stop only advising physical activity in adults with haemophilia. prescribe it now! The role of exercise therapy and nutrition in chronic musculoskeletal diseases. Haemophilia. 2016; 22: 554-556.

33. Stieltjes N, Torchet MF, Misrahi L, Roussel-Robert V, Lambert T, Guérois $\mathrm{C}$, et al. Epidemiological survey of haemophiliacs with inhibitors in France: orthopaedic status, quality of life and cost-the 'Statut Orthopedique des Patients Hemophiles' avec Inhibiteur study. Blood Coagul Fibrinolysis 2009; 20: 4-11.
34. Hilberg T, Herbsleb M, Puta C, Gabriel HHW, Schramm W. Physical training increases isometric muscular strength and proprioceptive performance in haemophilic subjects. Haemophilia. 2003; 9: 86-93.

35. Kargarfard M, Dehghadani M, Ghias R. The effect of aquatic exercise therapy on muscle strength and joint's range of motion in haemophilia patients. Int $\mathrm{J}$ Prev Med. 2013; 4: 50-56

36. Negrier C, Seuser A, Forsyth A, Lobet S, Llinas S, Rosas M. The benefits of exercise for patients with haemophilia and recommendations for safe and effective physical activity. Haemophilia. 2013; 19: 487-498.

37. Heijnen L. The role of rehabilitation and sports in haemophilia patients with inhibitors. Haemophilia 2008; 14: 45-51.

38. Cuesta-Barriuso R, Gómez-Conesa A, López-Pina JA. Physiotherapy treatment in patients with hemophilia and chronic ankle arthropathy: a systematic review. Rehabil Res Pract. 2013; 2013: 305249.
Ann Hematol Oncol - Volume 4 Issue 9 - 2017

ISSN : 2375-7965 | www.austinpublishinggroup.com

Cuesta-Barriuso. (C) All rights are reserved
Citation: Cuesta-Barriuso R. Effectiveness of Physiotherapy in the Treatment of Hemophilic Arthropathy a Systematic Review. Ann Hematol Oncol. 2017; 4(9): 1172. 